Lysosomal storage disorders (LSDs) highlight the diverse ways in which the failure of a single organelle can bring cells to their knees. Most are rare and poorly understood, making the development of therapies a daunting task. By Michael Eisenstein, infographic by Denis Mallet.

\section{BONE-MARROW TRANSPLANT}

This is an aggressive treatment in which the patient's blood-cell-producing haematopoietic stem cells are wiped out by chemotherapy and replaced with healthy donor cells.
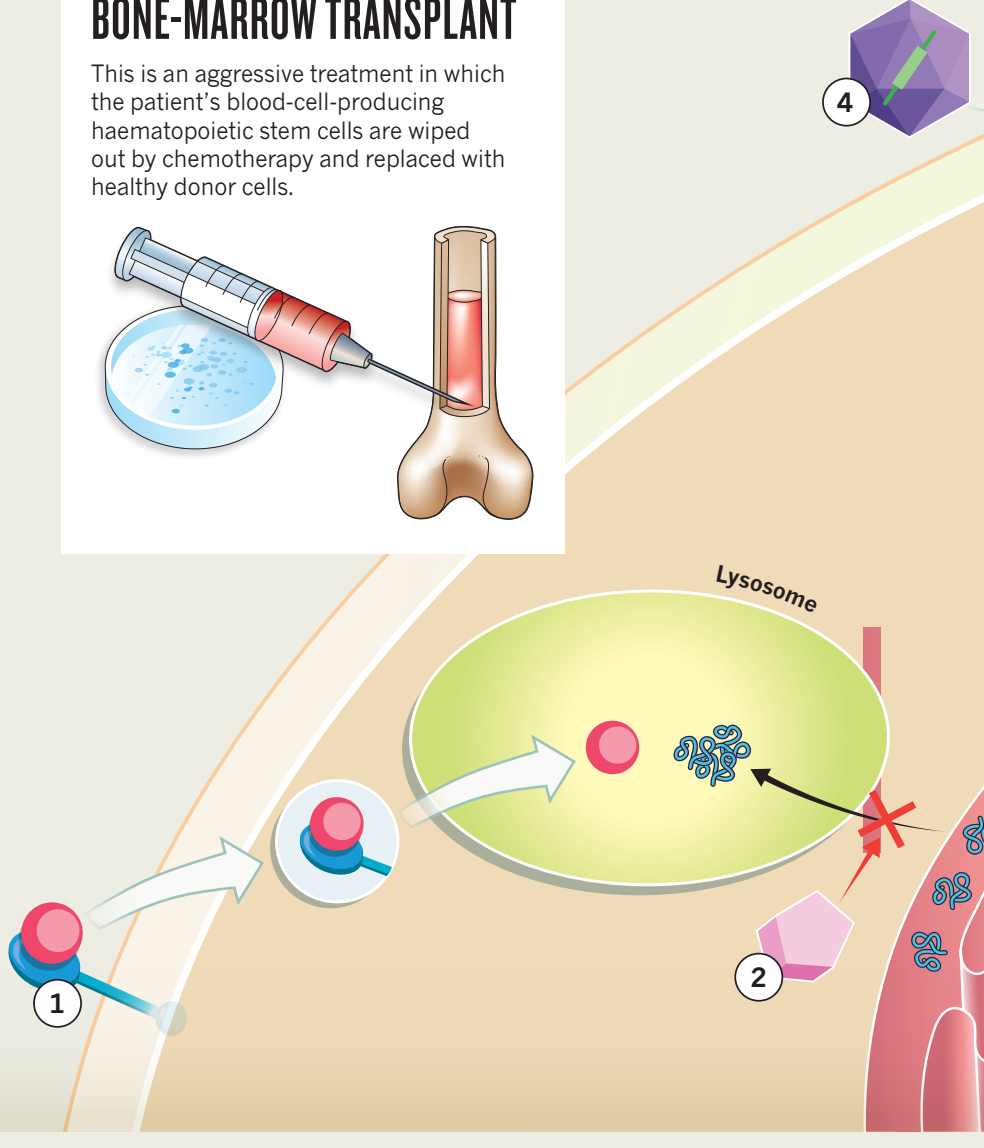

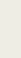

